\title{
Optimal design of fatigue loaded heavy-duty machine spring elements
}

\author{
H. Martikka ${ }^{1}$ \& I. Pöllänen ${ }^{2}$ \\ ${ }^{1}$ Department of Mechanical Engineering, \\ Lappeenranta University of Technology, Lappeenranta, Finland \\ ${ }^{2}$ SAV Oy Engineering, Finland
}

\begin{abstract}
The aim of this paper is to present results of using fundamental machine element design principles into re-designing optimally heavy-duty springs used in terrain machinery and in industry. The use of standard procedures often results in recurrent fatigue fracture failures. This reveals the need for optimal innovative design principles which are not found in standards. Analytical calculations reveal the main causes of failures to be the local bending due to eccentric highly impact force application at squared and ground ends and wearing away of the shot peening protection. Optimum design is used to solve the problem by finding the optimal spring. Goals are minimisation of wire volume, space restriction, desired spring rate, avoidance of surging and achieving reliably long fatigue life. Available fatigue dimensioning methods are used with amplitude-mean stress diagrams and S-N curve approaches. Conclusions are supported by using full 3D solid FEM analysis by which the stresses, strains, deformations and natural frequencies and modes are obtained. Then FEM is used to optimally fine tune and validate the best result.
\end{abstract}

Keywords: industrial optimisation, helical springs, fatigue.

\section{Introduction}

Background for this study is observation that conventionally designed helical springs did not have the expected long lifetime. Analyses of many case studies have gives gave clue that a additional effects contributed strongly, Among these are the highly impacting bending and torsional stress peaks due to non symmetric pressure application at ground spring ends. The conventional standards of dimensioning do not take these effects into account. 
Standard fatigue life estimates are based on static strengths and existence of only torsional stresses and give widely differing answers. This scatter can be taken into account using probabilistic and fuzzy approach. Generally optimisation is not yet often applied to practical problem according to Hernandez and Fontan [1]. One obstacle is difficulty of goal formulation and understanding of basic principles of machine design. Another obstacle is that problems are highly non-linear and have mostly discrete variables. Gradient type methods have proved inapplicable. One proven algorithm can be used to generate a restricted number of virtual prototypes and then select the one which appeals best to the end user.

The goals in this study are the following. First the main mechanism causing failure are identified and corrective redesign ideas are generated. Then systematic optimisation approach is activated. The model includes the models for dimensioning and fatigue life estimation presented in texts of Norton [2], Shigley and Mischke [3] and Spotts et al [4]. The goals are formulated to maximise fuzzy satisfaction on performance of deflection vs. load behaviours, reliable fatigue life, dynamic behaviour and space constraints.

\section{Materials and methods}

\subsection{Object of study}

The object of study is a range of helical compression springs which are used in heavy-duty application with very high life reliability requirements. Their main function is to store energy from displacements and also withstand shocks and impacts. Ground ends cause local bending moment as illustrated in Fig.1.

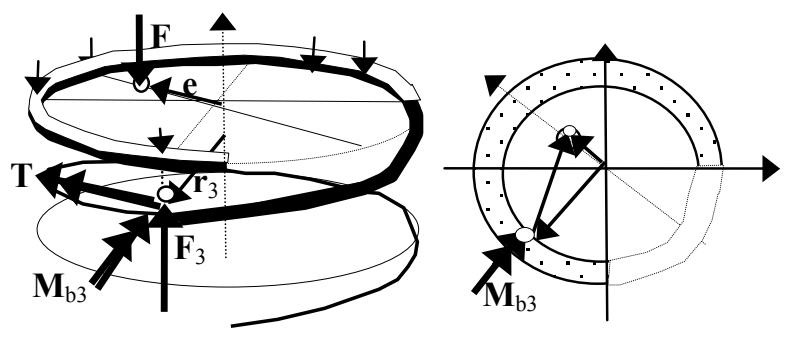

Figure 1: Definitions of helical spring with ground ends.

Definitions of spring variables and fuzzy satisfaction functions are shown in Fig.2. The fuzzy function $p_{\mathrm{x}}$ has max height unity, but area is not unity. Probability density function of mean value of property variable $x x$ is $p d f(x x)$, height is not unity but area is unity.

\subsection{Design goal formulation}

\subsubsection{The overall design goal}

This is to maximise the satisfaction $P(G)$ of end user customer on the realised design event, or a set denoted by $G$. It is a union of partial design events. The 
cost means now volume of the spring wire. Reliable functioning of the spring is achieved by using as desired properties the respective safety factors, SF. The space for the spring is restricted in width and height.

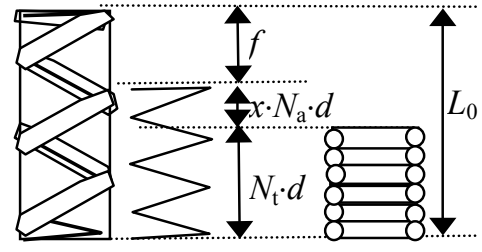

a)

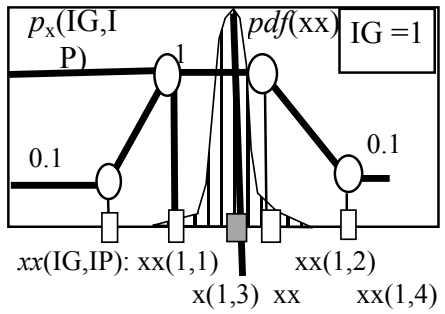

b)

Figure 2: Definitions. a) Spring variables. b) Satisfaction function.

$$
\begin{aligned}
& G=G_{1}(x x(1)=\text { cost }) \bullet G_{2}\left(x x(2)=N_{\text {goodm }}\right) \bullet G_{3}\left(x x(3)=N_{\text {misch }}\right) \\
& \bullet G_{4}\left(x x(4)=N_{\text {spott }}\right) \bullet G_{5}\left(x x(5)=N_{\text {taual }}\right) \bullet G_{6}\left(x x(6)=N_{\text {lifeA }}\right) \\
& \bullet G_{7}\left(x x(7)=f_{\text {surge }}\right) \bullet G_{8}\left(x x(8)=k_{\text {spring }}\right) \bullet G_{9}(x x(9)=\text { height })
\end{aligned}
$$

Total satisfaction of this design event is product of partial functions

$$
P(G)=P\left(G_{1}\right) \bullet P\left(G_{2}\right) \bullet P\left(G_{3}\right) \bullet P\left(G_{4}\right) \bullet P\left(G_{5}\right) \bullet P\left(G_{6}\right) \bullet P\left(G_{7}\right) \bullet P\left(G_{8}\right) \bullet P\left(G_{9}\right)
$$

\subsubsection{Design satisfaction functions}

These are defined on four points to give a trapezoidal form, Fig.2. Value of property, $x x(\mathrm{IG})$ with index IG is on horizontal scale and satisfaction $p_{\mathrm{x}}$ on $x x$ is on vertical scale, ranging from 0 no good to 1 unit or fully good. Machine element design methods are based on strength diagrams and theoretical and empirical relationships between their variables. If the mean value of a stochastic property $x x(\mathrm{IG})$ is within the most satisfactory range, and if its design value is normally distributed, then worse or better values may occur. Design is robust axiomatically when fuzzy range can be produced and the design range is in it.

\subsubsection{Discrete variables}

Optimum strategy was done by exhaustive search loops. Preliminary choices are (a) Choice of assuming not (Isp = 1) shot peening or yes (Isp = 2), (b) Choice of impact factor $V$, (c) choice of an assuming of volume fraction $f$ of inclusions,

1. Loop for material selection $\operatorname{Im}=1$ to $N_{\text {im }}$,

2. Loop for spring helix diameter $D(\mathrm{Idd})$ variation, $\mathrm{Idd}=1$ to NIdd

3. Loop for wire diameter $d(\mathrm{Id})$, variation, $\mathrm{Id}=1$ to NId

4. Loop for total number of coils $N_{\text {tot }}$ variation, INtot $=1$ to NINtot

\subsubsection{Material property data for optimisation}

Now a reasonable selection for materials is ASTM A232 chrome Vanadium steels AISI 6150. According to Norton [2] it is suitable for fatigue loading. 
Shear modulus is $G=79000 \mathrm{MPa}$. Ultimate tensile strength depends on the diameter $d$ of the wire

$$
R_{\mathrm{m}}=S_{\mathrm{ut}}=\frac{A}{d^{\mathrm{m}}}, R_{\mathrm{m}}[M P a], \quad d[\mathrm{~mm}], A=1880[\mathrm{MPa}], m=0.192
$$

The following definitions of strength values are derived by empirical relationships from the static tensile strength, $R_{\mathrm{e}}$ is yield strength in tension, $S_{\mathrm{ys}}$ is yield strength in torsion and $S_{\text {us }}$ is ultimate strength in shear

$$
R_{\mathrm{e}}=0.75 S_{\mathrm{ut}} \quad, S_{\mathrm{ys}}=(0.577 \ldots 0.6) S_{\mathrm{ut}} \quad, S_{\mathrm{us}}=0.67 S_{\mathrm{ut}}
$$

\subsubsection{Load stresses}

Load to the spring comes from a cam mechanism. Nominal shear stress depends on load force.

$$
\tau_{\mathrm{n}}=T_{\mathrm{nF}} \cdot F=\frac{8}{\pi} \frac{D}{d^{3}} \cdot F, \quad T_{\mathrm{nF}}=\frac{8}{\pi} \frac{D}{d^{3}}
$$

shear stress is maximal in the inner coil due to smallest curvature.

$$
\tau_{\mathrm{xy}, \mathrm{F}}=K_{\mathrm{w}} \tau_{\mathrm{n}}=K_{\mathrm{w}} T_{\mathrm{nF}} \cdot F=T_{\mathrm{F}} \cdot F \quad, T_{\mathrm{F}}=K_{\mathrm{w}} T_{\mathrm{nF}}
$$

where the correction factor $K_{\mathrm{w}}$ of nominal shear stress Spring force $F$ depends linearly by spring rate $k$ on deflection $f$

$$
F=\frac{G d^{4}}{8 N_{\mathrm{a}} D^{3}} f, \quad F=k f
$$

Shear stress dependence on deflection is

$$
\tau_{\mathrm{xy}, \mathrm{F}}=K_{\mathrm{k}} \cdot f=K_{\mathrm{w}} \frac{1}{\pi} \frac{d \cdot G}{D^{2} N_{\mathrm{a}}} \cdot f, \quad K_{w}=\frac{4 C-1}{4 C-4}+\frac{0.615}{C}, C=\frac{D}{d}
$$

The springs are generally pre-stressed with deflection $f=f_{\text {pre }}$. The mechanism using the spring gives additional deflection $f_{\text {cam }}$ and their sum is the maximum deflection and shear stresses

$$
f_{\text {pre }}=f_{\text {min }}, f_{\text {cam }}=\Delta h, f_{\text {max }}=f_{\text {min }}+f_{\text {cam }}, \quad \tau_{\min }=K_{k} f_{\min }, \quad \tau_{\max }=K_{k} f_{\max }
$$

The mean and amplitude shear stresses are

$$
\tau_{\text {mean }}=\frac{1}{2}\left(\tau_{\max }+\tau_{\min }\right), \quad \tau_{\text {ampl }}=\frac{1}{2}\left(\tau_{\max }-\tau_{\min }\right)
$$

\subsubsection{Properties evaluated by satisfaction functions}

2.2.6.1 Material cost of wire spring Cost is now wire material volume

$$
x x(1)=\text { Volume }=\text { Length } \bullet \text { Area }=\pi D N_{\mathrm{a}} \frac{\pi}{4} d^{2}, \quad N_{\mathrm{a}}=N_{\text {tot }}-2
$$


Here $N_{\text {tot }}$ is the total number of coils and $N_{\mathrm{a}}$ is the active number. It is 2 less due to the bent and ground end manufacturing.

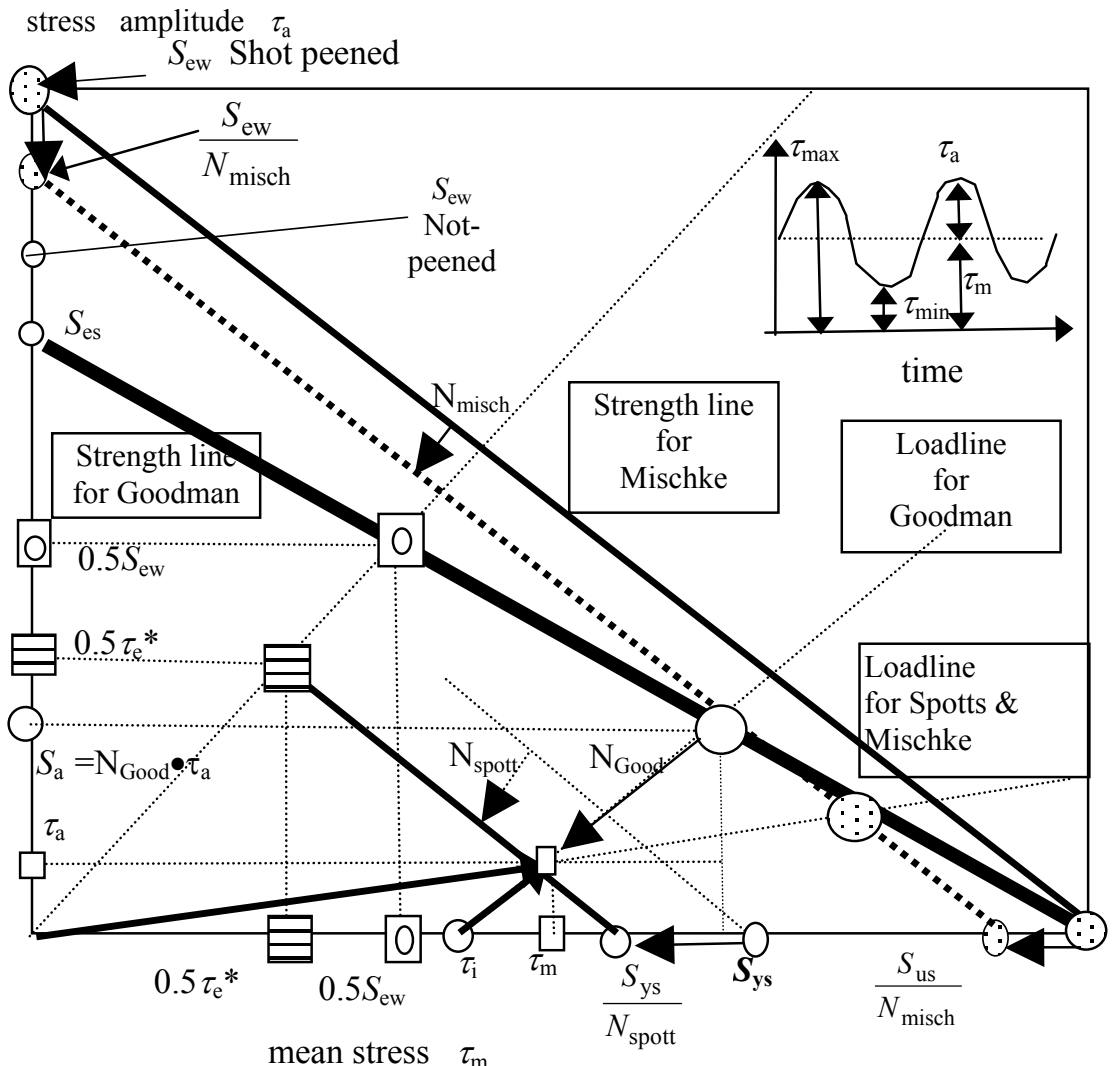

Figure 3: Comparison of the three torsional diagrams.

2.2.6.2 Torsional safety factor estimation using Goodman diagram Torsional Goodman diagram safety factor is based on the following definitions by Norton [2]. The torsional endurance strength is reversed strength $S_{\text {ew }}$ which is independent of size and alloy composition. $S_{\text {ew }}=310 \mathrm{MPa}$ applies for not shot peened springs or who have lost their protective layer. $S_{\mathrm{ew}}=465 \mathrm{MPa}$ applies for shot peened springs. Endurance shear stress is

$$
S_{\mathrm{es}}=\frac{0.5 S_{\mathrm{ew}} \cdot S_{\mathrm{us}}}{S_{\mathrm{us}}-0.5 S_{\mathrm{ew}}}
$$

The torsional safety factor by Goodman diagram [2] with dimensionless variables .In this model the basic stress level is the initial prestressing load defined as the minimum shear stress $\tau_{\mathrm{i}}$ defined as $\tau_{\min }$ at initial pre-stressing 


$$
N_{\text {Goodm }}=\frac{\left(1-\frac{\tau_{\mathrm{i}}}{S_{\mathrm{us}}}\right)}{\frac{\tau_{\mathrm{m}}-\tau_{\mathrm{i}}}{S_{\mathrm{us}}}+\frac{\tau_{\mathrm{a}}}{S_{\mathrm{es}}}}, \quad \tau_{\mathrm{i}}=\tau_{\min }, \quad x x(2)=N_{\mathrm{Goodm}}
$$

\subsubsection{Torsional safety factor estimation using Shigley-Mischke diagram}

Torsional safety factor by Shigley and Mischke [3] model is given by

$$
\frac{1}{N_{\text {Misch }}}=\frac{\tau_{\mathrm{a}}}{S_{\text {ew }}}+\frac{\tau_{\mathrm{m}}}{S_{\mathrm{us}}} \quad, \quad x x(3)=N_{\text {Misch }}
$$

2.2.6.4 Torsional safety factor estimation using Spotts et al diagram In this model by Spotts et al [4] the yield strength in shear $S_{\mathrm{ys}}$ is defined by a different factor than by Goodman in Norton [2]. They also define a pulsating shear stress endurance $\tau_{\mathrm{e}}$, These strength models are used in the model

$$
S_{y s}=0.51 S_{u t}, \tau_{e}{ }^{\prime}=0.2 S_{u t}, \quad \frac{K_{\mathrm{w}} \tau_{\mathrm{a}}}{\frac{S_{\mathrm{ys}}}{N_{\mathrm{spott}}}-\tau_{\mathrm{m}}}=\frac{\frac{1}{2} \tau_{\mathrm{e}}{ }^{\prime}}{S_{\mathrm{ys}}-\frac{1}{2} \tau_{\mathrm{e}}{ }^{\prime}}, x x(4)=N_{\text {spott }}
$$

2.2.6.5 Torsional safety factor estimation using an engineering method This is based on Finnish standard procedures [5]. No shot peening is assumed. The allowed stress is calculated from static tensile strength $R_{\mathrm{m}}$ using conservative strength reduction factors due to loading severity and amplitude magnitude

$$
N_{\text {taual }}=\frac{\tau_{\text {all }}}{\tau_{\text {max }}}, \tau_{\text {all }}=C_{\text {ampl }} \cdot C_{\text {life }} \cdot C_{\text {helical }} \cdot R_{\mathrm{m}}, \quad x x(5)=N_{\text {taual }}
$$

Here endurance utilisation reduction factor at large amplitudes is $C_{\text {ampl }}=0.8$, to ensure long life $C_{\text {longlife }}=.9$, to consider compression loading $C_{\text {helix }}=0.31$ and for tension loading 0.37 . Now the more conservative option 0.31 is chosen.

2.2.6.6 Surge frequency and spring rate The surge frequency by [4] should be higher than the main operational frequency of the machine $10 \mathrm{~Hz}$ by [3],

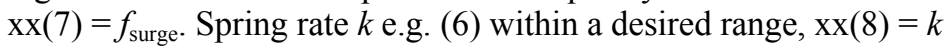

2.2.6.7 Fatigue life of spring by combining a Haigh diagram and the S-N diagram This method of calculating fatigue life $N_{\text {life }}$ combines the Haigh diagram of modified Goodman type and the S-N diagram by Meyer [6].

$$
N_{\text {life }}=10^{\mathrm{A}}, \quad A=\log \left[\frac{V_{\mathrm{a}} V_{e}}{\left(1-V_{\mathrm{m}}\right) c^{2}}\right]\left[\frac{3}{\log \left(V_{\mathrm{e}} / c\right)}\right], \quad x x(6)=A
$$

where three stress ratios are used

$$
V_{\mathrm{a}}=\frac{\sigma_{\mathrm{va}}}{R_{\mathrm{m}}}, \quad V_{\mathrm{m}}=\frac{\sigma_{\mathrm{vm}}}{R_{\mathrm{m}}}, \quad V_{\mathrm{e}}=\frac{S_{\mathrm{e}}}{R_{\mathrm{m}}}, \quad c=0.9
$$


here $V_{\mathrm{a}}$ is relative effective stress amplitude, $V_{\mathrm{m}}$ is relative effective mean stress and $V_{\mathrm{e}}$ is relative effective corrected fatigue strength. In these

$$
\sigma_{\mathrm{vm}}=\left(\sigma_{\mathrm{m}}^{2}+3 \tau_{\mathrm{m}}^{2}\right)^{1 / 2}, \quad \sigma_{\mathrm{va}}=\left(\sigma_{\mathrm{a}}^{2}+3 \tau_{\mathrm{a}}^{2}\right)^{1 / 2}
$$

The dynamic normal stress is dangerous in springs. It has been observed often that cracks occur at angle $\alpha=20^{\circ}$. If they are normal to max. principal stress then the ratio of max. $\sigma_{x}$ stress to shear stress is about 2 at angle $20^{\circ}$, Fig 5 .

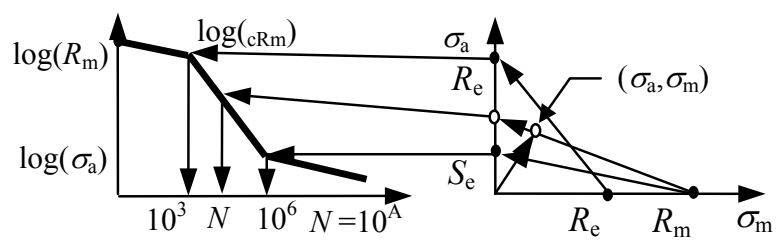

Figure 4: The method of calculating fatigue lives of crack initiation time from normal mean stress and amplitude stress vs. S-N diagram.

The ideal fatigue strength or the mean endurance limit of the rotating-bending specimens of steels can be calculated from static strength. The regression fit formula by Just [7] is used since is that it gives dependence on $Z$. Bellot and Gantois [8] give data for the effect of volume fraction $f$ of inclusions on $Z(\mathrm{f})$. In strong constructional steels with $R_{\mathrm{m}}=950 \mathrm{MPa}$, parameter $A=1700$. Fracture strain is obtained by a tensile test of material

$$
\varepsilon_{\mathrm{f}}(Z)=\ln \left[\frac{1}{1-Z}\right]=\varepsilon_{\mathrm{fp}}(f) \Rightarrow Z=1-e^{-\varepsilon_{\mathrm{f}}(Z)}
$$

using this one obtains for the dependency of the ideal bending fatigue strength with zero mean strength on the static tensile strength

$$
\sigma_{\mathrm{w}}=k_{\mathrm{Rm}} R_{\mathrm{m}}, \quad k_{\mathrm{Rm}}(f)=0.26+0.45 \cdot Z_{\mathrm{f}} \quad, \quad Z_{f}=Z_{0} \frac{1}{1+f \cdot A}
$$

The fully corrected fatigue strength is $S_{\mathrm{e}}$

$$
S_{\mathrm{e}}=\frac{1}{K_{\mathrm{f}}} \sigma_{\mathrm{e}}=C_{\mathrm{f}} C_{\mathrm{k}} \sigma_{\mathrm{w}} \Rightarrow S_{\mathrm{e}}=C_{\mathrm{f}} C_{\mathrm{p}} C_{\mathrm{t}} C_{\mathrm{r}} C_{\mathrm{s}} C_{\mathrm{z}} C_{\mathrm{m}} \sigma_{\mathrm{w}}=C_{\text {total }} \sigma_{\mathrm{w}}
$$

Now the total factor is about unity. Eccentricity is obtained as, Fig.1

$$
e_{\mathrm{c}}=e_{\mathrm{cR}} \cdot \frac{1}{2} D, \quad e_{\mathrm{cR}}=0.3
$$

Static bending stress at critical section at $1+1 / 8$ turns is

$$
\sigma_{\mathrm{xF}}=\frac{e_{c R} \frac{1}{2} D}{\frac{\pi}{32} d^{3}} \bullet F=\frac{16}{\pi} \frac{e_{\mathrm{cR}} D}{d^{3}} \bullet F=S_{\mathrm{xF}} \cdot F
$$


Static shear stress vs. force $F$ is given by equation

$$
\tau_{\mathrm{xy}, \mathrm{F}}=K_{\mathrm{w}} \tau_{\mathrm{n}}=K_{\mathrm{w}} T_{\mathrm{nF}} \cdot F=T_{\mathrm{F}} \cdot F \quad, \quad T_{\mathrm{F}}=K_{\mathrm{w}} T_{\mathrm{nF}}
$$

Principal stress is dominant in activating fatigue crack initiation, $\sigma_{\mathrm{y}}=0$

$$
\sigma_{1}=\frac{1}{2} \sigma_{\mathrm{x}}+\sqrt{\left(\frac{1}{2} \sigma_{\mathrm{x}}\right)^{2}+\tau_{\mathrm{xy}}^{2}}
$$

The maximum and minimum values of stress depend on load force $F=k f$.

Now at principal direction the shear stress is zero and the mean values of principal stress and amplitude are equal to the equivalent values

$$
\sigma_{1, \text { mean }}=\frac{1}{2}\left(\sigma_{1, \max }+\sigma_{1, \min }\right) \Rightarrow \sigma_{v m} \quad, \quad \sigma_{1, \text { ampl }}=\frac{1}{2}\left(\sigma_{1, \max }-\sigma_{1, \min }\right) \Rightarrow \sigma_{v a}
$$

2.2.6.8 Impact on the spring end The rotating moving mass of the cam hits an elastic steel body of a spring producing impact stress. Typical cams rotate with frequency $f=8 \mathrm{~Hz}$, period $T=1 / f=1 / 8 \mathrm{sec}$.Cam rise $s=\Delta h=0.046 \mathrm{~m}$, rise time is about $\Delta t=x T=0.1 \cdot 1 / 8$. It is assumed that the rise takes place during 0.1 of the full rotation angle. The impactor mass $M$ hits the object mass $m$ of spring. This gives rise to axial speed v0s and an impact factor V, Burr and Cheatham [11]

$$
v_{0 \sigma}=\frac{\Delta h}{\Delta t}=3.5 \frac{m}{s} \quad, \quad V=\sqrt{\frac{1}{\beta}\left(\frac{1}{1+\frac{1}{3} \beta}\right)}, \beta=\frac{m}{M}
$$

here $\beta$ is mass ratio of object mass $m$ and impactor mass $M$. The following definitions are needed

$$
U=\frac{2 e_{c R}}{K_{\mathrm{w}}} \quad, \quad T_{\mathrm{F}}=K_{\mathrm{w}} T_{\mathrm{nF}} \quad T_{\mathrm{nF}}=\frac{8}{\pi} \frac{D}{d^{3}}
$$

The static stresses in the spring are related as follows

$$
\tau_{\mathrm{xyF}}=T_{\mathrm{F}} F \quad, \quad \sigma_{\mathrm{x}, \mathrm{F}}=U \cdot \tau_{\mathrm{xy}, \mathrm{F}}
$$

The normal stress induced by impact is assumed as

$$
\sigma_{\mathrm{i}}=\frac{\Delta h}{\Delta t} \sqrt{E \rho} \bullet V=\sigma_{0} V \quad, \quad \sigma_{0}=\frac{\Delta h}{\Delta t} \sqrt{E \rho}
$$

The shear stress induced by impact is $\tau_{\text {im }}$

$$
\tau_{0}=\frac{d}{D} \sqrt{\frac{G}{E}} \bullet \sigma_{0}=H \bullet \sigma_{0}, \quad \tau_{\text {im }}=\tau_{0} \bullet V \sigma_{\mathrm{i}}=\sigma_{0} \bullet V
$$

The resultant stresses are assumed to be sum of the continuously varying static stress due to force $F$ and the very short time impact stresses

$$
\tau_{x y}=\tau_{\mathrm{xy}, \mathrm{F}}+H \sigma_{0} V \quad, \quad \sigma_{x}=\sigma_{\mathrm{xy}, \mathrm{F}}+\sigma_{0} V
$$



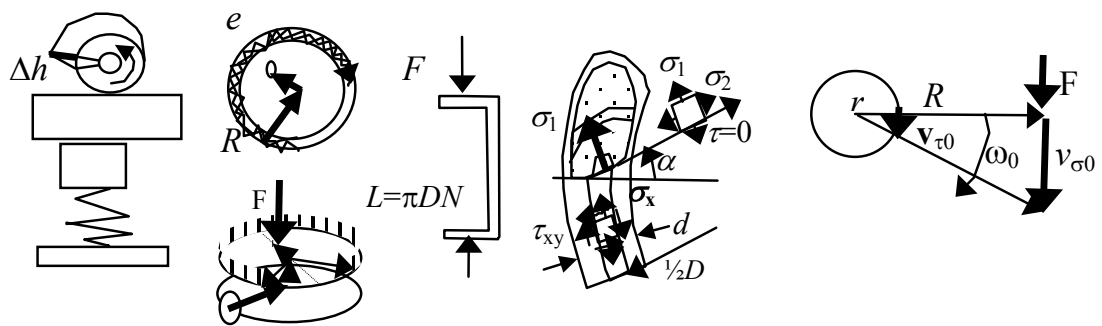

Figure 5: Definitions of impacting loads causing shear and normal stress impacts. Angle of crack is often $\alpha=20^{\circ}$.

\subsubsection{Normalised height needed to fit the spring into given space}

Free length $L_{0}$ for spring is sum of fully compressed length $L_{\mathrm{c}}$, $=N_{\mathrm{t}} d$ reserve and $S_{\mathrm{a}}=x d N_{\mathrm{a}}$ and usable deflection $f$. Data fit to DIN 2095 [10] gives factor x (C).

$$
\begin{gathered}
x=0.00115(C-4)^{2}+0.02(C-4)+0.1, d \geq 0.8 m m \\
\text { height }=\frac{L_{0, \text { calculated }}}{L_{0, \text { given }}}=\left(N_{\mathrm{a}}[1+x]+2\right)+\frac{f}{L_{0}} \Rightarrow 1 \pm \Delta=x x(9)
\end{gathered}
$$

\subsubsection{Satisfaction function for each property}

These are defined at four points at Table 1.

Table 1: $\quad$ Satisfaction functions for properties.

\begin{tabular}{|l|l|l|l|l|l|}
\hline IG & $\begin{array}{l}\text { Property } \\
\mathrm{px}(\mathrm{IG}, \mathrm{IP})\end{array}$ & $\begin{array}{l}\mathrm{IP}=1 \\
0.1\end{array}$ & $\begin{array}{l}\mathrm{IP}=2 \\
1\end{array}$ & $\begin{array}{l}\mathrm{IP}=3 \\
1\end{array}$ & $\begin{array}{l}\mathrm{IP}=4 \\
0.1\end{array}$ \\
\hline 1 & $\mathrm{xx}(1)=K$ & 1 & 2 & 3 & 500 \\
\hline 2 & $\mathrm{xx}(2)=N_{\text {goodm }}$ & 0.1 & 2 & 3 & 4 \\
\hline 3 & $\mathrm{xx}(3)=N_{\text {misch }}$ & 0.1 & 2 & 3 & 4 \\
\hline 4 & $\mathrm{xx}(4)=N_{\text {spott }}$ & 0.1 & 2 & 3 & 4 \\
\hline 5 & $\mathrm{xx}(5)=N_{\text {taual }}$ & 0.1 & 2 & 3 & 4 \\
\hline 6 & $\mathrm{xx}(6)=\mathrm{A}, N_{\text {life }}=10^{\mathrm{A}}$ & 0.1 & 8 & 15 & 20 \\
\hline 7 & $\mathrm{xx}(7)=f_{\text {surge }}$, & 20 & 30 & 500 & 800 \\
\hline 8 & $\mathrm{xx}(8)=k^{*} 10^{-3}$ & 20 & 40 & 50 & 100 \\
\hline 9 & $\mathrm{xx}(9)=$ height & .90 & .97 & 1.02 & 1.10 \\
\hline
\end{tabular}

\section{Results}

Results are shown in Table 2. Here the spring rate $k=44000 \mathrm{~N} / \mathrm{m}$, $e_{\mathrm{R}}=$ eccentricity $/ 0.5 \mathrm{D}, V=4$ is impact factor. Safety factor $\mathrm{N}_{\text {taual }}$ is for no shot peening, $\mathrm{P}(\mathrm{G})$ is total satisfaction. Angle of principal stress to axis $\alpha=28^{\circ}$ which is larger that measured $20^{\circ}$. 
Table 2: Results of optimisation. Analysed cases are R1..R6. Geometry code 564 are optimal choices: $d(5)=0.014, D(6)=0.12, N_{\mathrm{t}}(4)=7$.

\begin{tabular}{|l|l|l|l|l|l|l|l|l|l|}
\hline Case & $\mathrm{R} 1$ & $\mathrm{R} 2$ & $\mathrm{R} 3$ & $\mathrm{R} 4$ & $\mathrm{R} 5$ & $\mathrm{R} 6$ & $\begin{array}{l}d(\mathrm{Itt}) \\
(\mathrm{m})\end{array}$ & $\begin{array}{l}D(\mathrm{Idd}) \\
(\mathrm{m})\end{array}$ & $\mathrm{N}_{\text {tot }}$ \\
\hline $\mathrm{e}_{\mathrm{R}}$, & 0.3 & 0.0 & 0.3 & 0.3 & 0 & 0 & 0.008 & 0.070 & 4 \\
\hline Isp & 1 & 1 & 1 & 2 & 2 & 2 & 0.009 & 0.080 & 5 \\
\hline$f$, incl. & 0 & 0 & 0.01 & 0.01 & 0.01 & 0 & 0.010 & 0.090 & 6 \\
\hline$N_{\text {goodm }}$ & 1 & 1 & 1 & 1.5 & 1.5 & 1.5 & 0.012 & 0.10 & 7 \\
\hline$N_{\text {misch }}$ & 1.33 & 1.33 & 1.33 & 1.65 & 1.65 & 1.65 & $\mathbf{0 . 0 1 4}$ & 0.11 & 8 \\
\hline$N_{\text {spott }}$ & 0.56 & 0.56 & 0.56 & 0.56 & 0.56 & 0.56 & 0.016 & $\mathbf{0 . 1 2}$ & - \\
\hline$N_{\text {taual }}$ & 0.67 & 0.67 & 0.67 & 0.67 & 0.67 & 0.67 & - & - & - \\
\hline $\mathrm{A}$, life & 8 & 11.6 & 5.4 & 5.4 & 7.2 & 11.6 & - & - & - \\
\hline $\mathrm{P}(\mathrm{G})$ & 0.017 & 0.017 & 0.0017 & 0.008 & 0.020 & 0.030 & - & - & - \\
\hline
\end{tabular}

From Table 2 it may be seen the following trends with rather high impact $V=4$ :

- An optimal case R6 has total satisfaction is as 0.03 when there is no eccentricity, shot peening protection is preserved even at high impact $V=4$ loading, and inclusion content is minimal using high quality steel.

- Still more optimal case is obtained from case R6 by setting $V=0$ and $e_{\mathrm{R}}=0$, $f=0$.High life with $A=13.2$ and angle $\alpha=45$ are obtained as by pure torsion.

- The angle $\alpha$ between $\mathrm{x}$-axis and largest principal stress at case R1 varied with $V: V=0, \alpha=45$, when $V=4, \alpha=28$, with high impacts $V=20, \alpha=11$.

\subsection{FEM analysis results}

The MSC Nastran FEM [12] program is used. Geometry is shown in Fig. 6.

The dimensions in the case study of FEM in Fig. 6 were $d=10 \mathrm{~mm}$, $D=100 \mathrm{~mm}$, total number of coils $N_{\text {tot }}=8$. The end were not ground or bent, but the load was applied by an even distribution of point forces.

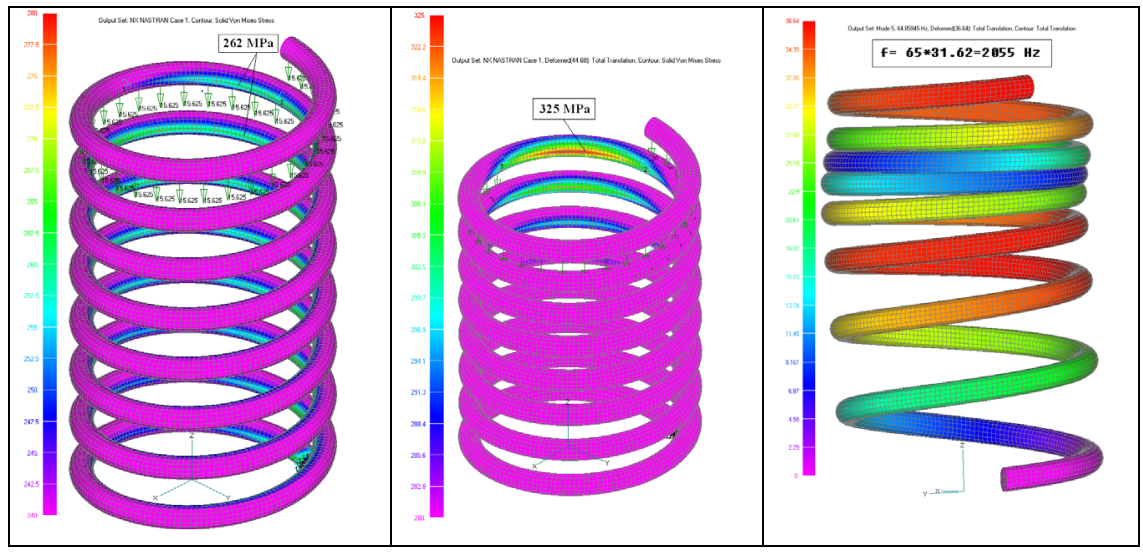

Figure 6: $\quad$ Spring results. a) Symmetric loading $360^{\circ}$ on the top of the spring; b) Non symmetric loading $270^{\circ}$; c) Natural frequency $2055 \mathrm{~Hz}$. 
Effectively 1 coil was fixed. Analytical spring rate was $k=14000 \mathrm{~N} / \mathrm{m}$ FEM gave the same. The von Mises stress on surface of the non symmetric loading is $325 \mathrm{MPa}$ and for symmetric loading von Mises stress is $263 \mathrm{MPa}$. First natural frequency causing upper turns to impact to each other is $2055 \mathrm{~Hz}$.

\section{Conclusions}

The following conclusions can be drawn.

- Standards assume in helical springs only torsional stresses with no bending with impacts which arise due to eccentric load force application.

- Impact loading increases the static torsion and but more bending stresses. Life time predictions decrease by many decades. The predicted angle of the largest principal stress relative to axis is close to observed angles.

- Shot peening gives protection by compressive surface residual stresses . But notable wear between coils can delete it from critical areas.

- Inclusions at critical bent surface areas reduce lifetimes notably.

- Optimal design dimensioning guarantees satisfactory long reliable service life

- FEM analyses reveal stress gradients agreeing with the analytical results.

\section{References}

[1] Hernandez, S. \& Fontan, A. N., Practical Applications of Design Optimization, WIT Press, Southampton, Boston, 2002

[2] Norton, R. L., Machine Design. An Integrated Approach. Pearson Prentice Hall, 2006

[3] Shigley, J. E. \& Mischke, C. R., Mechanical Engineering Design, McGraw Hill Book Co., 1989

[4] Spotts, M. F., Shoup, T. E. \& Hornberger, L.E., Design of Machine Elements, Pearson Education International, 2004

[5] Finnish standard procedures, Technical Information 3/82. Material selection. Springs. Metalliteollisuuden kustannus Oy,1982,56p.

[6] Meyer, J.A. Finite life under combined stress, Machine Design, August, 1985, pp.83-84.

[7] Just, E., Brucheinschnurung und Schwingfestigkeit. Fortschritte der VDIZeitschriften.Reihe 5, 1976, H.28, pp.1-40.

[8] Bellot, I., Gantois, M., The influence of "sulphide.type" inclusions on the mechanical properties of constructional steels,(1978) Transactions ISIJ, Vol.18, 1978, pp.546-553.

[9] Hundal, M-S, Power shaft design with PC's. Machine Design, May 9, 1985, pp.82-84.

[10] DIN 2095 German Standard.

[11] Burr, A. H., Cheatham, J. B., Mechanical Analysis and Design, Prentice Hall, 1995

[12] MSC Nastran FEM program. 